\title{
Solubility of Stevioside and Rebaudioside A in water, ethanol and their binary mixtures
}

\author{
Liliana S. Celaya ${ }^{a^{*}}$, Eugenio KolB ${ }^{\mathrm{a}}$, And Nicolás KolB ${ }^{\mathrm{a}^{*}}$ \\ ${ }^{a}$ Faculty of Exact, Chemistry and Life Sciences, National University of Misiones, Félix de Azara 1552, \\ 3300-Posadas, Argentina \\ ${ }^{*}$ Corresponding author \\ lilianacelaya@hotmail.com,nkolb@fceqyn.unam.edu.ar \\ TEL: $+54-0376-4435049$ \\ FAX: +54-0376-4425414
}

Received: 16 September 2015; Published online: 18 October 2016

\begin{abstract}
In order to investigate the solubility of Stevioside and Rebaudioside A in different solvents (ethanol, water, ethanol:water 30:70 and ethanol:water 70:30), supersaturated solutions of pre-crystalized steviol glycosides were maintained at different temperatures (from $5{ }^{\circ} \mathrm{C}$ to $50{ }^{\circ} \mathrm{C}$ ) to reach equilibrium. Under these conditions significant differences were found in the extent of solubility. Rebaudioside A was poorly soluble in ethanol and water, and Stevioside was poorly soluble in water. Solvent mixtures more effectively promoted solubilisation, and a significant effect of temperature on solubility was observed. The two steviol glycosides showed higher solubilities and this behavior was promoted by the presence of the other sweetener. The polarity indices of the solvents were determined, and helped to explain the observed behavior. Several solute-solvent and solute-solute interactions can occur, along with the incidence of a strong affinity between solvents. The obtained results are in accordance with technological applications of ethanol, water and their binary mixtures for Stevioside and Rebaudioside A separations.
\end{abstract}

Keywords: Stevia sweeteners; Solubility; Crystallization; Ethanol; Water; Temperature

\section{Introduction}

The Paraguayan herb Stevia rebaudiana (Bert) Bertoni, commonly called "Ka-Hee", "stevia" or "hierba dulce" (sweet herb) is a rich source of natural sweeteners named steviol glycosides (SGs). In recent years, these phytochemicals have gained great attention (Carakostas, Prakash, Kinghorn, Wu, \& Soejarto, 2012; Chranioti, Chanioti, \& Tzia, 2016). Stevia sweeteners are used in many countries within a range of food formulations and for different pharmaceutical purposes.

SGs are organic moieties that have active hydrophilic (glycoside) and hydrophobic (diterpene) groups (Upreti, Strassburger, Chen, Wu,
\& Prakash, 2011). Stevioside (Stv) and Rebaudioside $\mathrm{A}(\mathrm{RbA})$ are the main SGs extracted from stevia (Carakostas et al., 2012; Kolb, Herrera, Ferreyra, \& Uliana, 2001). RbA, which has an extra glucose unit relative to Stv, is superior in terms of both sweetness and quality of taste (Chranioti, Chanioti, \& Tzia, 2015). Physicochemical properties of these sweeteners also differ from one another.

Several studies have described the ability of SG to improve the solubility of other sweeteners or biomolecules (Lee, 2011; Goto \& Clemente, 1998; Zhang et al., 2011; Uchiyama, Tozuka, Nishikawa, \& Takeuchi, 2012). Other studies explore the capability of SGs to form different crystalline forms in addition to the amorphous form 
(Carakostas et al., 2012; Lee, 2011; Prakash, DuBois, Cios, Wilkens, \& Fosdick, 2008, 2008; Upreti et al., 2011). Solvents play an important role in physicochemical processes including extraction, solubilization and crystallization (Kerton, 2013; Reichardt, 2004a). Water is the selected solvent for the recovery of SGs from stevia leaves and it is preferred for the development of new pharmaceutical or food additives (Abelyan, Markosyan, \& Abelyan, 2011; Rai, Majumdar, \& De, 2012; Lee, 2011; Uchiyama et al., 2012). These systems include SGs, among other biomolecules or components, in complex matrices that can inhibit the crystallization of sweeteners, keeping them in suspension or dissolution. However, water is not appropriate industrially for the final steps in purification of SGs. Such operations normally include solubilizations or crystallizations, made with alcoholic solvent (Abelyan et al., 2011; Carakostas et al., 2012; Jonnala, Babu, Vijay, \& Paramvir, 2006; Kumar, 1986; Markosyan, 2011; Prakash, G., G., \& Upreti, 2015; Persinos, 1973).

In pure water, the reported solubilities of Stv and RbA were only $8 \mathrm{~g} / \mathrm{L}$ and $1.3 \mathrm{~g} / \mathrm{L}$ (at room temperature) (Kinghorn, 2002). In alcohols such as ethanol or methanol, SGs exhibit differential behaviour (Kinghorn, 2002; Carakostas et al., 2012; Jonnala et al., 2006; Persinos, 1973). However, the existing information about the characteristics of these differences is scarce. There are no previous reports describing the variation in solubility of SGs in water, ethanol or their mixtures with temperature.

In the present study, two premises were considered. First, the solubilization and crystallization process cannot only be affected by changing the temperature but also by changing the solvent polarity. Second, when solubilization and crystallization are carried out jointly they can take a long time to reach equilibrium (Kerton, 2013; Jones, 2002; Reichardt, 2004a). Based on these premises, we investigated the solubility of Stv and $\mathrm{RbA}$ in water, ethanol and binary mixtures (ethanol:water), at different temperatures (from $5{ }^{\circ} \mathrm{C}$ to $50{ }^{\circ} \mathrm{C}$ ), in order to determine the effect of the polarity of each solvent on this physicochemical property.

\section{Materials and Methods}

\section{$2.1 \quad$ Materials}

Solvents were purchased from various suppliers: ethanol 99.5\% bought from Cicarelli (Reagents S.A., San Lorenzo, Argentina) and water was deionised using a water purification system. HPLC grade acetic acid, acetonitrile, water and ethanol from Merck (Darmstadt, Germany). Other chemicals used were of analytical grade. Stevia sweeteners were obtained from in-house purification work on stevia samples according to Kolb et al. (2001). Crystals of Stv (purity of $95.0 \%$ ) and RbA (purity of 99.5\%) were obtained by crystallization from pure methanol and ethanol, as determined by chromatographic analysis (HPLC). These isolated SGs were used as standard compounds for HPLC and were assayed in the solubilization study.

\section{$2.2 \quad$ Solubility study}

The solvents employed in the study were ethanol, water, ethanol:water 30:70 (w/w) and ethanol:water 70:30 (w/w). Binary mixtures were prepared by mixing pure solvents in adequate proportion to obtain dissolutions with density according to reported values (Poling, Thomson, Friend, Rowley, \& Wilding, 2008). Densities were measured with a precision densimeter (FITE, Argentina). The empirical polarity indices $E T(30)$ and the normalized polarity indices $E T(N)$ were estimated as described below. Densities, proportion solvent:solvent (v/v), ET(30) and $E T(N)$ for the solvents are listed in Table 1. The experimental conditions for the solubility study were defined by preliminary assays. First, sweeteners were vacuum dried to constant weight (at $60{ }^{\circ} \mathrm{C}$ ). Then, tubes containing $4000 \mathrm{mg}$ of crystals in $10 \mathrm{~mL}$ of solvent were sonicated at $50{ }^{\circ} \mathrm{C}$ for $60 \mathrm{~min}$. The set of tubes, hermetically sealed, was maintained at $5{ }^{\circ} \mathrm{C}$ for five days to promote solubilization or crystallization.

For higher temperatures, mixtures of dry sweeteners and solvent (4000 $\mathrm{mg}$ in $10 \mathrm{~mL}$ of solvent) were sonicated $(60 \mathrm{~min})$ at the temperature of the assay and kept in a thermostatic system (Shott Gerate, model CTI 150, USA) with recirculation 
of a heating fluid. The time of experimentation was 48 hours and the temperatures were $30{ }^{\circ} \mathrm{C}$, $35{ }^{\circ} \mathrm{C}, 40{ }^{\circ} \mathrm{C}, 45^{\circ} \mathrm{C}$ and $50{ }^{\circ} \mathrm{C}$.

Solubility for the mixture Stv:RbA (1:1 w/w) was also tested in binary solvents too. The experiment was repeated twice, and the higher value of concentration was considered as the saturation solubility for each condition.

\section{$2.3 \quad$ Steviol glycosides concentration}

The concentration of solubilized SGs was assayed with HPLC-DAD using the external standards method according to Kolb et al. (2001). The test mixtures were quickly centrifuged and the supernatant was diluted in ethanol, ethanol:water or water to obtain convenient dissolutions for the assay (in ethanol:water 70:30 w/w). A SHIMADZU LC-20 AT prominence chromatograph was employed with the following operating conditions: column zorbax amino of $4.6250 \mathrm{~mm}$; detector: UV at $210 \mathrm{~nm}$; detector sensitivity adjusted to 0.04 AUF; ambient temperature; mobile phase: acetonitrile:water 80:20 (v/v) and $\mathrm{pH}$ 5. For the calibration curve, stock solutions of $0.3,0.6$ and $1.0 \mathrm{~g} / \mathrm{L}$ of standard compounds in ethanol:water 70:30 (w/w) were prepared. The parameters for external calibration curves were obtained by fitting experimental data through linear regression from replicate injections of standard solutions. The compounds in each sample were identified by comparing their retention times with those of the standards.

\section{Results and Discussion}

\subsection{Solubility in water}

The solubility curves of Stv and RbA in pure water at different temperatures are shown in Fig. 1.A (and Table 2). Sweeteners pre-crystalized in water are poorly soluble in this solvent $(<8 \mathrm{~g} / \mathrm{L})$. Solubility presents slight variation (from $5{ }^{\circ} \mathrm{C}$ to $50{ }^{\circ} \mathrm{C}$ ) but does not increase significantly with increasing temperature (Fig. 1.A). This behaviour is in accordance with previously reported data of water solubility for these SGs (Upreti et al., 2011; Kinghorn, 2002).
As it is well known, stevia sweeteners are difficult to dissolve in water. This behavior does not change with the temperature, and crystallization was the principal phenomenon in the polar solvent (from $5{ }^{\circ} \mathrm{C}$ to $50{ }^{\circ} \mathrm{C}$ ). Solubility values are in contrast with previous data for SGs concentrations in more complex systems (Goto \& Clemente, 1998; Rai et al., 2012; Uchiyama et al., 2012), suggesting that other components (organic moieties or compounds of the complex matrix) can influence the crystallization or solubilization phenomena as well as the crystalline or amorphous form of SGs.
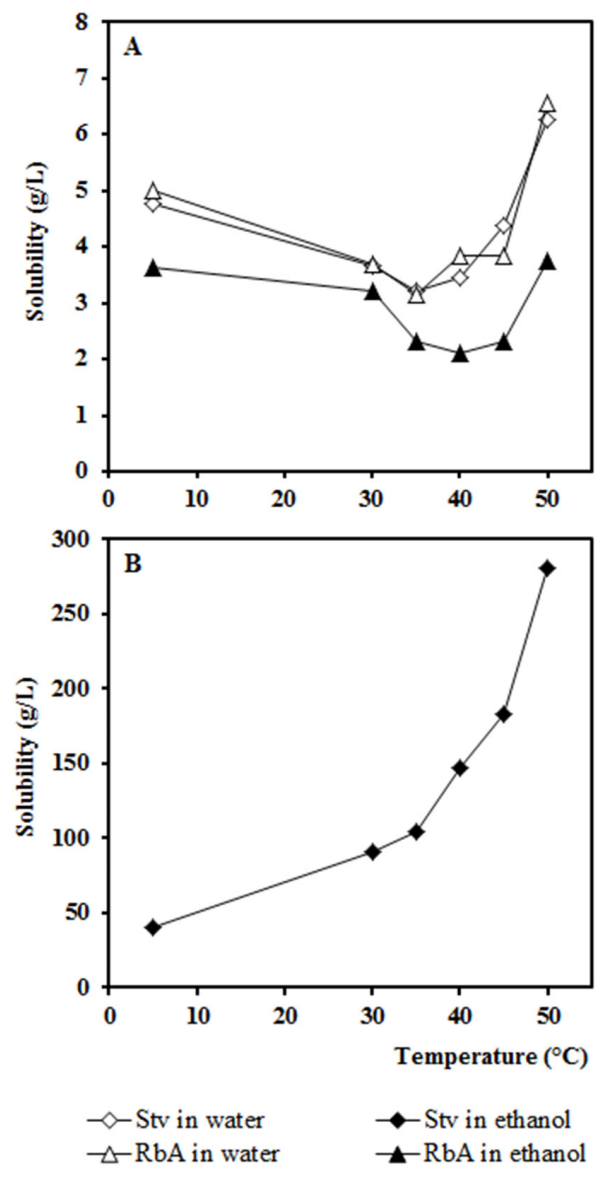

Figure 1: Solubility of (A) RbA and Stv in water, RbA in ethanol, (B) Stv in ethanol 
Solubility of Stevioside and Rebaudioside A | 161

Table 1: Physicochemical properties of ethanol, water and their binary mixtures $\left(25{ }^{\circ} \mathrm{C}\right)$

\begin{tabular}{lllll}
\hline Solvent mixture & $\begin{array}{l}\text { Density } \\
(\mathrm{g} / \mathrm{mL})^{a}\end{array}$ & $\begin{array}{l}\text { Ethanol:water } \\
(\mathrm{v} / \mathrm{v})^{b}\end{array}$ & $\begin{array}{l}\text { Polarity Index, } \\
E T(30)^{c, d}\end{array}$ & $\begin{array}{l}\text { Normalized polarity } \\
\text { index, ET }(N)^{c, d}\end{array}$ \\
\hline Pure water & 0.997 & 0.0 & 63.1 & 1.000 \\
Ethanol:water 30:70 (w/w) & 0.951 & 35.9 & 53.7 & 0.710 \\
Ethanol:water 70:30) (w/w) & 0.863 & 76.4 & 53.0 & 0.690 \\
Pure ethanol & 0.785 & 100.0 & 51.9 & 0.654 \\
\hline
\end{tabular}

Data and calculations from: ${ }^{a}$ Poling, Thomson, Friend, Rowley, and Wilding (2008); ${ }^{b}$ Helbing and Burkart (1985); ${ }^{c}$ Reichardt (2004b); ${ }^{d}$ Langhals (1991)

Table 2: Solubility of Stv (g/L) and RbA (g/L) in water, ethanol:water 30:70, ethanol:water 70:30 and ethanol

\begin{tabular}{|c|c|c|c|c|c|c|c|c|}
\hline \multirow{3}{*}{$\begin{array}{r}\text { Solvent mixture } \\
\text { Temperature }\left({ }^{\circ} \mathrm{C}\right)\end{array}$} & \multicolumn{8}{|c|}{ Solubility (g/L) } \\
\hline & \multicolumn{2}{|c|}{$0: 100$} & \multicolumn{2}{|l|}{$30: 70$} & \multicolumn{2}{|l|}{$70: 30$} & \multicolumn{2}{|l|}{ 100:0 } \\
\hline & Stv & $\overline{\mathrm{RbA}}$ & Stv & $\mathrm{RbA}$ & Stv & $\overline{\mathrm{RbA}}$ & Stv & $\overline{\mathrm{RbA}}$ \\
\hline 5 & 4.7 & 5.0 & 4.5 & 7.1 & 42.2 & 56.2 & 40.5 & 3.6 \\
\hline 30 & 3.7 & 3.7 & 34.8 & 33.9 & 102.3 & 72.8 & 91.1 & 3.2 \\
\hline 35 & 3.2 & 3.2 & 51.0 & 50.1 & 132.9 & 86.6 & 104.0 & 2.3 \\
\hline 40 & 3.4 & 3.8 & 87.8 & 80.4 & 190.0 & 105.7 & 147.4 & 2.1 \\
\hline 45 & 4.4 & 3.8 & 133.6 & 117.1 & 241.5 & 124.1 & 182.9 & 2.3 \\
\hline 50 & 6.3 & 6.6 & 177.8 & 156.8 & 310.3 & 213.7 & 281.3 & 3.7 \\
\hline
\end{tabular}

Table 3: Solubility of Stv:RbA (g/L) in ethanol:water 30:70 and ethanol:water 70:30

\begin{tabular}{lllll}
\hline \multirow{2}{*}{$\begin{array}{l}\text { Solvent mixture } \\
\text { Temperature }\left({ }^{\circ} \mathrm{C}\right)\end{array}$} & Solubility $(\mathrm{g} / \mathrm{L})$ \\
\cline { 2 - 5 } & Stv & RbA & Stv & RbA \\
\hline 5 & 148.3 & 146.6 & 80.2 & 95.9 \\
30 & 127.7 & 140.3 & 149.9 & 153.6 \\
35 & 136.4 & 138.8 & 167.4 & 158.4 \\
40 & 151.5 & 162.1 & 170.6 & 169.4 \\
45 & 189.6 & 230.9 & 173.1 & 189.2 \\
50 & $>400.0$ & $>400.0$ & 181.8 & 214.9 \\
\hline
\end{tabular}

IJFS | October 2016 | Volume 5 | pages 158-166 


\subsection{Solubility in ethanol}

The solubility curves of Stv and RbA in ethanol at different temperatures are shown in Fig. 1.A and Fig. 1.B (Table 2). RbA exhibited poor solubility in ethanol and the equilibrium line was flat $(<4.0 \mathrm{~g} / \mathrm{L})$ from $5{ }^{\circ} \mathrm{C}$ to $50{ }^{\circ} \mathrm{C}$ (Fig. 1.A). Stv showed higher values, with a strong concentration temperature dependence: $40.5 \mathrm{~g} / \mathrm{L}$ at $5{ }^{\circ} \mathrm{C}$ rising sharply to $281.3 \mathrm{~g} / \mathrm{L}$ at $50{ }^{\circ} \mathrm{C}$ (Fig. 1.B). The capability of some alcohols to promote SG solubilization or crystallization was traditionally a separation mode for stevia sweeteners. The results obtained are in accordance with previously reported innovations, which use ethanol or ethanol with a low percentage of water to separate $\mathrm{Stv}$ from $\mathrm{RbA}$ by preferential solubilization of Stv and crystallization of RbA (Abelyan et al., 2011; Evans et al., 2010; Jackson, Francis, \& Chase, 2011; Jonnala et al., 2006; Kienle, 1992; Kumar, 1986; Markosyan, 2011).

\subsection{Solubility in binary mixtures}

The solubility curves of Stv and RbA in ethanol:water (30:70) are shown in Fig. 2.A (Table 2 and Table 3). The characteristic HPLC chromatogram for SGs alone is shown in Fig. 3. In these systems, there is an increase of the solubility with temperature. Stv concentration rises sharply from 4.5 and $177.8 \mathrm{~g} / \mathrm{L}$ and from 7.1 to $156.8 \mathrm{~g} / \mathrm{L}$ for $\mathrm{RbA}\left(5{ }^{\circ} \mathrm{C}\right.$ to $\left.50{ }^{\circ} \mathrm{C}\right)$. In the mixture, the increase of the solubility with the temperature was favored by the other SG (see Fig. 3.A). Stv concentration at $5{ }^{\circ} \mathrm{C}$ was $148.3 \mathrm{~g} / \mathrm{L}$ and rapidly increased to $>400 \mathrm{~g} / \mathrm{L}$ at $50{ }^{\circ} \mathrm{C}$. The same occurs with $\mathrm{RbA}$ and its solubility varying from $146.6 \mathrm{~g} / \mathrm{L}\left(5{ }^{\circ} \mathrm{C}\right)$ to $>400 \mathrm{~g} / \mathrm{L}\left(50{ }^{\circ} \mathrm{C}\right)$. As can be seen, crystallization of each SG is limited by the presence of the other SG and the solubility is favored by the mixture, increasing continuously with temperature.

Solubility curves of SGs in ethanol:water 70:30 depending on temperature are shown in Fig. 2.B (Table 2 and Table 3). For Stv or RbA alone, concentration rises sharply from 42.2 and 56.2 $\mathrm{g} / \mathrm{L}\left(5^{\circ} \mathrm{C}\right)$ to 310.3 and $213.7 \mathrm{~g} / \mathrm{L}$ at $50{ }^{\circ} \mathrm{C}$, respectively. In the mixture, there is an increase of the solubility with temperature. For Stv, it changes from 80.2 to $181.8 \mathrm{~g} / \mathrm{L}$. For RbA, concentration ranges from 95.9 to $214.9 \mathrm{~g} / \mathrm{L}$ (from 5 to $50{ }^{\circ} \mathrm{C}$ ). The crystallization phenomenon was not promoted by ethanol:water 70:30 for SG alone or in the mixture. However, a minor solubilization was shown, when comparing this binary solvent with ethanol:water 30:70.

In general, solvent mixtures more effectively promoted the solubilization phenomena and this behavior was favored by the presence of other SGs and a higher percentage of water in the binary solvent. The temperature had a significant effect on these variations.

\subsection{Solvents polarity and solubilization}

In order to study hydroalcoholic mixtures as solvent, $E T(30)$ and $E T(N)$ were used as proposed by (Koshima, Nakamoto, Aracava, Oliveira, \& Rodrigues, 2015). ET(30) in $\mathrm{Kcal} / \mathrm{mol}$ and $E T(N)$ dimensionless, were calculated according to 1 (Langhals, 1991) and 2 (Reichardt, 2004b):

$$
\begin{gathered}
E T(30)=E_{D} \ln \left[\left(C_{p} / C^{*}\right)+1\right]+E T(30)^{0} \\
E T(N)=\frac{E T(30)-30.7}{32.24}
\end{gathered}
$$

For ethanol:water mixtures, $E_{D}$ and $C^{*}$ values are $2.04 \mathrm{Kcal} / \mathrm{mol}$ and $5.47 \mathrm{~mol} / \mathrm{L}$, respectively (Langhals, 1991); $C p$ is the molar concentration of water $(\mathrm{mol} / \mathrm{L})$ and $E T(30)^{0}$ is the $E T(30)$ index related to ethanol:water (Reichardt, 2004b). Values of $E T(30)$ and $E T(N)$ are listed in Table 1. $E D(30)$ for water is $63.1 \mathrm{Kcal} / \mathrm{mol}$ and 51.9 $\mathrm{Kcal} / \mathrm{mol}$ for ethanol (Reichardt, 2004b). For pure ethanol or water, it is well know that there is a similarity between these solvents (Kerton, 2013; Reichardt, 2004b), however, water is more polar and has a great solvation power.

Similar values of $E D(30)$ were estimated for binary mixtures with $30 \%$ of water $(53.7 \mathrm{Kcal} / \mathrm{mol})$ and $70 \%$ of water $(53.0 \mathrm{Kcal} / \mathrm{mol})$. These results are consistent with the behavior observed before with these binary solvents from $30 \%$ to $70 \%$ of ethanol (da Silva, Ricken, Silva, \& Machado, 2002).

Considering the dimensionless scale of $E T(N)$, it varies from 0.000 for the least polar solvent 

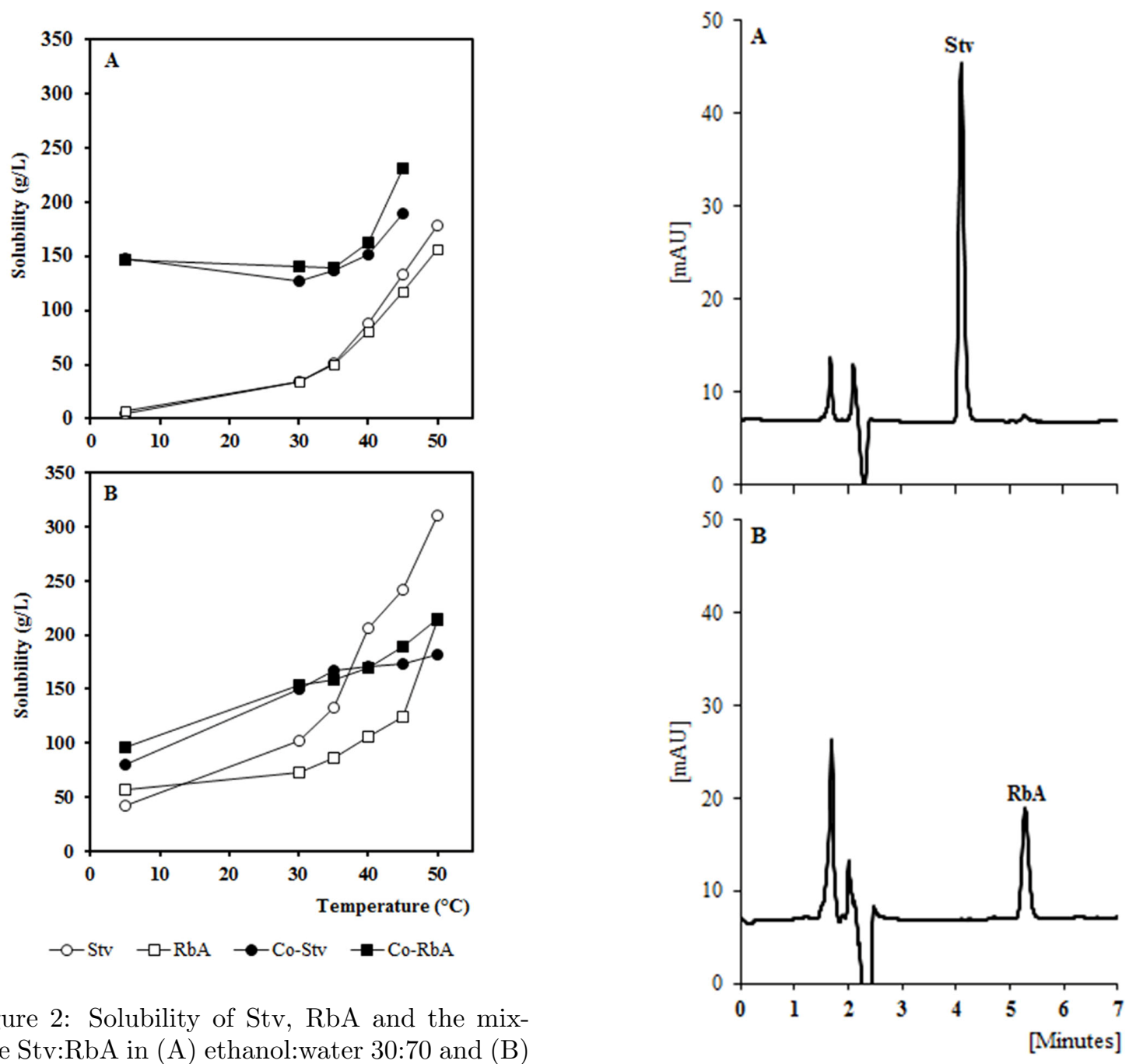

Figure 2: Solubility of Stv, RbA and the mixture Stv:RbA in (A) ethanol:water 30:70 and (B) ethanol:water 70:30; Co-RbA, Rebaudioside A in mixtures of SGs; Co-Stv, Stevioside in mixtures of SGs

Figure 3: HPLC chromatogram for ethanol:water 30:70 solution (detection at $210 \mathrm{~nm}$ ): (A) Stv, (B) $\mathrm{RbA}$ 
(tetramethylsilanethe) to 1.000 for the most polar solvent (water); with a value of 0.654 for ethanol (Reichardt, 2004b).

In mixtures, the $E T(N)$ were 0.690 and 0.710 for solvents with $70 \%$ and $30 \%$ of ethanol, respectively (Table 1). Many properties of solvents are dependent on their molecular structure (Kerton, 2013). For binary mixtures, the intermolecular interactions can be described by several factors which determine the mutual solubility and the polarity or the solvation power (Kerton, 2013; Reichardt, 2004b). Between ethanol and water, hydrogen bond interactions are really important. For their binary mixtures, the polarity can be used to predict the solubility of different compounds (Kerton, 2013; Reichardt, 2004b). This property increases as the value of water mass fraction in the solvent increases (Koshima et al., 2015).

In relation to the behaviour of sweeteners, an important consideration is that SGs are organic moieties with glycoside groups linked to the hydrophobic portion (diterpene). SGs can interact among themselves but the glycoside groups are limited in the ways they can interact with the solvent. On the other hand, the solubility should be considered in conjunction with the crystallization process in ethanol and water. The results obtained may be explained by the existence of competition between SGs-solvents (solubilization) and SG-SG (crystallization) interactions, and the incidence of a strong affinity between solvents in all the cases. In this respect, crystallization phenomenon cannot only be affected by changing solubility with changing temperature but also by changing solubility with changing solvent polarity (Reichardt, 2004a). The concept of polarity (or solvation power) is not straightforward because the solvent can be involved in different ways with the solubilizing species (Kerton, 2013; Reichardt, 2004b).

In pure water with $E T(N)=1.000$, interactions SG-SG are superior to interactions SG-solvent and the sweeteners preferentially crystallize. In ethanol, $E T(N)=0.654$, RbA with an extra glucose unit crystallizes and Stv is solubilized showing a good behaviour with increasing temperature up to $50{ }^{\circ} \mathrm{C}$.

In binary solvents with $E T(N)=0.690$ and 0.710 (for $70 \%$ and $30 \%$ of ethanol), the solvent po- larity can affect the SG-SG interactions and the nucleation of sweeteners (Jones, 2002; Reichardt, 2004a). In these systems, higher solubilities were observed as in most cases Stv and RbA were not capable of producing crystalline forms. Each SG can inhibit the crystallization of the other $\mathrm{SG}$, and this behavior is enhanced by increasing temperature. Finally, in ethanol:water 30:70, higher interactions are possible between glycosides groups and water (which has the highest solvation power) and the solubility can be enhanced.

The results presented in this study are in accordance with the industrial applications of ethanol, water and their mixtures but are not conclusive. The polarity or the solvation ability of the solvents can partially explain the solubilization of SGs. However, further investigations and additional confirmation will be needed to infer the true nature of both SG-SG and SG-solvent interactions in ethanol:water mixtures.

\section{Conclusions}

The solubility of Stv and RbA in ethanol, water and their mixtures was studied. The results obtained are in accordance with technological applications of this solvent for Stv and RbA separations. RbA was poorly soluble in ethanol and water whilst Stv was poorly soluble in water. In general, binary solvents more effectively promoted the solubilization phenomena, and there was a significant effect of the temperature on solubility. This behaviour was favored by the presence of a high percentage of water in the binary mixture. In ethanol:water, the solubility was also promoted by the presence of other sweeteners, and each SG inhibited the crystalization of the other SG. The polarity or solvation power of ethanol, water or mixing solvents can partially explain the solubilization of stevia sweeteners. Several favourable or unfavourable SGs-solvent and SG-SG interactions can occur, along with the incidence of a strong affinity between solvents. 


\section{Acknowledgements}

The authors would like to thank Cristina Mayol M. A. for her critical English revision.

\section{References}

Abelyan, V., Markosyan, A., \& Abelyan, L. (2011). High-purity Rebaudioside D. United States Patent Database. Patent Application Publication US/2011/0092684A1.

Carakostas, M., Prakash, I., Kinghorn, D., Wu, C. D., \& Soejarto, D. S. (2012). Alternative sweeteners, fourth edition. In L. O'BrienNabors (Ed.), (Chap. Steviol Glycosides, pp. 159-180). Taylor \& Francis Group. Boca Raton London New York: CRC Press. doi:10.1201/b11242-13

Chranioti, C., Chanioti, S., \& Tzia, C. (2015). Microencapsulation of steviol glycosides (Stevia rebaudiana Bertoni) by a spray drying method - Evaluation of encapsulated products and prepared syrups. International Journal of Food Studies, 4, 212220. doi:10.7455/ijfs/4.2.2015.a9

Chranioti, C., Chanioti, S., \& Tzia, C. (2016). Comparison of spray, freeze and oven drying as a means of reducing bitter aftertaste of steviol glycosides (derived from Stevia rebaudiana Bertoni plant) - Evaluation of the final products. Food Chemistry, 190, 1151-1158. doi:10.1016/j. foodchem.2015. 06.083

da Silva, D. C., Ricken, I., Silva, M. A. D., \& Machado, V. G. (2002). Solute-solvent and solvent-solvent interactions in the preferential solvation of Brooker's merocyanine in binary solvent mixtures. Journal of Physical Organic Chemistry, 15(7), 420-427. doi:10.1002/poc.519

Evans, J. C., Hahn, J. J., Myerson, A. S., Oolman, T., Rhonemus, T. A., Storo, K. M., \& Tyler, C. A. (2010). Method for producing purified Rebaudioside A compositions using solvent / antisolvent crystallization. United States Patent Database. Patent Application Publication US/2010/0099857A1.

Goto, A. \& Clemente, E. (1998, April). Influência do Rebaudiosídeo A na solubilidade e no sabor do Esteviosídeo. Food Science and Technology (Campinas), 18, 3-6. doi:10 . 1590/S0101-20611998000100002

Helbing, W. \& Burkart, A. (1985). Tablas químicas: para laboratorios e industria. (Chap. Mezclas líquido / líquido, Vol. 69, p. 132). Reverté.

Jackson, M. C., Francis, G. J., \& Chase, G. (2011). Pure and substantially pure rebaudioside A. United States Patent Database. Patent Application Publication US/2011/0207918A1.

Jones, A. G. (2002). Crystallization process systems. (Chap. 3, pp. 61-62). ButterworthHeinemann, 1st Edition. London: Elsevier. Jonnala, K. K., Babu, G. D. K., Vijay, K. K., \& Paramvir, S. A. (2006). Process for production of steviosides from Stevia rebaudiana Bertoni. United States Patent Database. Patent Application Publication US/2006/0142555.

Kerton, F. M. (2013). Introduction. In James H. Clark \& George A. Kraus (Ed.), Alternative solvents for green chemistry (2) (pp. 1-30). The Royal Society of Chemistry. doi:10.1039/9781849736824-00001

Kienle, U. (1992). Method of making a natural sweetener based on Stevia rebaudiana, and use thereof. United States Patent Database. Patent Aplication Publication US/1992/5112610.

Kinghorn, A. D. (2002). Overview: Physical properties, solubility and stability of Stevioside. In A. D. Kinghorn (Ed.), (Chap. Medicinal and Aromatic Plants - Industrial Profiles: The Genus Stevia, Vol. 19, 1, pp. 8-9). Taylor \& Francis Group. London, New York: CRC Press. Retrieved from http://vanveenorganics. com / ebooks / Stevia \% 20 - \%20The \% 20Genus \% 20Stevia \% $20 \%$ 5BMedicinal \% 20 and $\%$ 20Aromatic $\%$ 20Plants $\% 5$ D \% 20 $\%$ 20A.\%20Kinghorn $\% 20$ (Taylor $\% 20$ and $\%$ 20Francis, \%202002)\%20WW.pdf

Kolb, N., Herrera, J. L., Ferreyra, D. J., \& Uliana, R. F. (2001). Analysis of sweet diterpene glycosides from Stevia rebaudiana: Improved HPLC method. Journal of Agricultural and Food Chemistry, 49(10), 4538-4541. doi:10.1021/jf010475p 
$166 \mid$ Celaya et al.

Koshima, C. C., Nakamoto, K. T., Aracava, K. K., Oliveira, A. L., \& Rodrigues, C. E. C. (2015). Fractionation of Bergamot and Lavandin Crude Essential Oils by Solvent Extraction: Phase Equilibrium at $298.2 \mathrm{~K}$. Journal of Chemical and Engineering Data, 60(1), 37-46. doi:10.1021/ je $500581 \mathrm{~h}$

Kumar, S. (1986). Method for recovery of Stevioside. United States Patent Database. Patent Application Publication US/1986/4599403.

Langhals, H. (1991). Description of properties of binary solvent mixtures. (Chap. 42 - Similarity models in organic chemistry, biochemistry and related fields, pp. 287-298). Elsevier Science Publishers.

Lee, T. (2011). Method to Increase Solubility Limit of Rebaudioside $\mathrm{D}$ in an Aqueous Solution. United States Patent Database. Patent Aplication Publication US/2011/0104353A1.

Markosyan, A. (2011). High-purity Rebaudioside $\mathrm{C}$ and process for purification the same. United States Patent Database. Patent Application Publication US/2011/0287164A1.

Persinos, G. J. (1973). Method of producing Stevioside. United States Patent Database. Patent Application Publication US/1973/3723410.

Poling, B. E., Thomson, G. H., Friend, D. G., Rowley, R. L., \& Wilding, W. V. (2008). Section 2 - Physical and Chemical Data. Table 2-112. (pp. 2-117). In McGraw-Hill Companies Editions. Perry's Chemical Engineers' Handbook, 8th Edition. United States: McGraw-Hill.

Prakash, I., DuBois, G. E., Cios, J. F., Wilkens, K. L., \& Fosdick, L. E. (2008). Development of rebiana, a natural, non-caloric sweetener. Food and Chemical Toxicology, 46(7, S), S75-S82. doi:10.1016/j.fct.200805.004

Prakash, I., G., D., G., K., \& Upreti, M. (2015). Rebaudioside A composition and method for purifying rebaudioside A. United States Patent Database. Patent Application Publication US/2015/9012626.

Rai, C., Majumdar, G. C., \& De, S. (2012). Optimization of Process Parameters for Wa- ter Extraction of Stevioside using Response Surface Methodology. Separation Science and Technology, 47(7), 1014-1022. doi:10. 1080/01496395.2011.641055

Reichardt, C. (2004a). Solvents and Solvent Effects in Organic Chemistry: Third, Updated and Enlarged Edition. (WILEYVCH Verlag GmbH \& Co. KGaA, Weinheim. Germany: Wiley-VCH, Chap. Appendix 5, Vol. 126, 14, pp. 487-489). ACS Publications. doi:10.1021/ja040904a

Reichardt, C. (2004b). Solvents and Solvent Effects in Organic Chemistry: Third, Updated and Enlarged Edition. (WILEYVCH Verlag GmbH \& Co. KGaA, Weinheim. Germany: Wiley-VCH, Chap. Empirical Parameters of Solvent Polarity, Vol. 126, 14, pp. 389-470). ACS Publications. doi:10.1021/ja040904a

Uchiyama, H., Tozuka, Y., Nishikawa, M., \& Takeuchi, H. (2012). Nanocomposite formation between alpha-glucosyl stevia and surfactant improves the dissolution profile of poorly water-soluble drug. International Journal of Pharmaceutics, 428(1-2), 183186. doi:10.1016/j.ijpharm.2012.01.016

Upreti, M., Strassburger, K., Chen, Y. L., Wu, S., \& Prakash, I. (2011). Solubility Enhancement of Steviol Glycosides and Characterization of Their Inclusion Complexes with Gamma-Cyclodextrin. International Journal of Molecular Sciences, 12(11), 75297553. doi:10.3390/ijms12117529

Zhang, F., Koh, G. Y., Jeansonne, D. P., Hollingsworth, J., Russo, P. S., Vicente, G., .. Liu, Z. (2011). A Novel SolubilityEnhanced Curcumin Formulation Showing Stability and Maintenance of Anticancer Activity. Journal of Pharmaceutical Sciences, 100(7), 2778-2789. doi:10.1002/jps. 22512 